\title{
Hermetia illucens larvae as a potential dietary protein source altered the microbiota and modulated mucosal immune status in the colon of finishing pigs
}

Miao Yu ${ }^{1,2,3,4}$, Zhenming $\mathrm{Li}^{1,2,3,4}$, Weidong Chen ${ }^{1,2,3,4}$, Ting Rong ${ }^{1,2,3,4}$, Gang Wang ${ }^{1,2,3,4}$ and Xianyong Ma $a^{1,2,3,4^{*}}$ (D)

\begin{abstract}
Background: Insects, such as Hermetia illucens larvae, are rich in chitin and proteins, and represent a suitable feed ingredient replacement for animals. However, little is known about the effect of administering $H$. illucens larvae on intestinal microbiota, bacterial metabolite profiles, and mucosal immune status in animals. This study aimed to investigate the effects of administering $H$. illucens larvae on colonic microbiota and bacterial metabolites production in finishing pigs. Seventy-two crossbred (Duroc $\times$ Landrace $\times$ Large White) female pigs (initial body weight, $76.0 \pm 0$. $52 \mathrm{~kg}$ ) were randomly allocated to three different dietary treatments: a control diet (Control group) and two diets corresponding to 4\% (H1 group) and 8\% (H2 group) H. illucens larvae inclusion levels, respectively. Each treatment consisted of eight pens (replicates), with three pigs per pen. After 46 days of feeding, eight pigs per treatment $(n=$ 8) were slaughtered, and the colonic digesta and mucosa were collected for microbial composition and microbial fermentation products, and genes expression analyses.

(Continued on next page)
\end{abstract}

\footnotetext{
* Correspondence: maxianyong@gdaas.cn

${ }^{1}$ Institute of Animal Science, Guangdong Academy of Agricultural Sciences,

Guangzhou 510640, Guangdong, People's Republic of China

${ }^{2}$ State Key Laboratory of Livestock and Poultry Breeding, Guangzhou 510640,

Guangdong, People's Republic of China

Full list of author information is available at the end of the article
}

(c) The Author(s). 2019 Open Access This article is distributed under the terms of the Creative Commons Attribution 4.0 International License (http://creativecommons.org/licenses/by/4.0/), which permits unrestricted use, distribution, and reproduction in any medium, provided you give appropriate credit to the original author(s) and the source, provide a link to the Creative Commons license, and indicate if changes were made. The Creative Commons Public Domain Dedication waiver (http://creativecommons.org/publicdomain/zero/1.0/) applies to the data made available in this article, unless otherwise stated. 
(Continued from previous page)

Results: The results showed that the $\mathrm{H} 1$ diet significantly increased the abundance of Lactobacillus, Pseudobutyrivibrio, Roseburia, and Faecalibacterium compared with those in the control group $(P<0.05)$, with a decrease in the abundance of Streptococcus. The numbers of Lactobacillus, Roseburia, and Clostridium cluster XIVa were significantly greater in the $\mathrm{H} 1$ group than in the control group $(P<0.05)$. Meanwhile, $\mathrm{H} 2 \mathrm{diet}$ increased the number of Clostridium cluster XIVa compared with the control group $(P<0.05)$. For colonic metabolites, total short chain fatty acids, butyrate, and isobutyrate concentrations were significantly higher in the $\mathrm{H} 1$ group than those in the control group $(P<0.05)$; the $\mathrm{H} 1$ treatment caused a striking decrease in protein fermentation compared with the control group, as the concentrations of total amines, cadaverine, tryptamine, phenol, $p$-cresol, and skatole were significantly lower $(P<0.05)$. Additionally, $\mathrm{H} 2$ diet also increased butyrate concentration compared with control group $(P<0.05)$, while decreased the concentrations of phenol, $p$-cresol, and skatole $(P<0.05)$. Pigs in the $\mathrm{H} 1 \mathrm{group}$ down-regulated the expression of TLR-4 and pro-inflammatory cytokines (IFN- $\gamma)$ compared with pigs in the control group $(P<0.05)$, and up-regulated anti-inflammatory cytokine $(I L-10)$ and intestinal barrier genes (ZO-1, occludin, and mucin-1). $\mathrm{H} 2$ diet up-regulated the expression of $Z$ O-1 compared with control group $(P<0.05)$. Furthermore, the changes in the colonic mucosal gene expression were associated with changes in the bacterial composition and their metabolites.

Conclusions: Collectively, dietary inclusion of Hermetia illucens larvae may enhance mucosal immune homeostasis of pigs via altering bacterial composition and their metabolites. These findings provide a new perspective on insect meal as a sustainable protein source rich in nutrient ingredients for swine.

Keywords: Colon, Finishing pigs, Hermetia illucens larvae, Immune status, Microbial metabolites, Microbiota

\section{Background}

The global population will exceed 9 billion in 2050, so the demand for meat is expected to be $58 \%$ higher in 2050 than its 2010 level [1]. In parallel, this affects the demand for livestock feeds, and places heavy pressure on the already overexploited resources, especially protein sources. Therefore, more and more researchers are interested in finding new alternative and sustainable protein sources for livestock feed. Several insect species, such as the Hermetia illucens, as a sustainable food alternative and the feed ingredients are an interesting natural resource when considering their many environmental and health benefits [2, 3]. H. illucens larvae provide a high nutritive value feedstuff as they are rich in protein (40-44\%) with a similar or even more balanced amino acid (AA) composition than soybean meal [4]. As the feed ingredients of a complete diet, H. illucens larvae have been found to modulate growth performance, nutrient digestibility, and blood profiles of chickens $[5,6]$. Additionally, dietary including $4 \%$ and $8 \%$ H. illucens larvae in weaning piglets had no negative effects on the growth performance and nutrient digestibility [7]. Thus, these results demonstrate that $H$. illucens larvae can be used in the diet of monogastric animals as a potential valuable feed ingredient.

In addition, $H$. illucens larvae also contain bacteriostatic substances, such as chitin, which is a naturally occurring polysaccharide of the arthropod's exoskeleton and considered to be one of the most abundant biopolymers in nature [8]. Chitin resists the digestion and absorption in the small intestine of monogastric animals, and enters the large intestine for use by the microbiota as a fermentable substrate. A previous study in piglets indicated that chitin derivatives (such as chitosan) administered can potentially reduce or inhibit the proliferation of pathogenic bacteria causing post weaning diarrhea [9]. Indeed, the effects of $H$. illucens larvae as a feed ingredient on the gut microbiota $[5,10,11]$ and microbial metabolites (such as short-chain fatty acids, SCFAs) $[5,11]$ have been described in the cecal digesta of laying hens or broiler chickens, suggesting an evident effect of $H$. illucens larvae on the gut microbiota and metabolism. However, it remains unclear whether the $H$. illucens larvae meal as a dietary protein source has evident effect on the gut microbiota and its metabolism in the colon of finishing pigs.

As the first of innate immune response, the gastrointestinal epithelium represents a physical and an immunological barrier, and plays a significant role in maintenance and regulation of gastrointestinal health. Alteration of the bacterial community and their metabolite profile could affect intestinal immune function. Accumulating evidence has indicated that bacterial products resulting from carbohydrate fermentation, such as SCFAs exert many beneficial effects on physiological function of the intestine as they not only provide energy for epithelial cells, stimulate epithelial proliferation and tight junction formation, but also inhibit potential pathogen growth, inflammation and genotoxicity $[12,13]$, while bacterial metabolites from protein fermentation, such as amines, ammonia, indolic and phenolic compounds are considered to exert negative effects on the intestinal mucosa by interfering with its inflammatory responses $[13,14]$. The previous study has indicated that $H$. 
illucens larvae as an alternative feed additive increased frequency of CD4+ lymphocyte in broiler chicks [15], which indicated that $H$. illucens larvae may have the potential to positively affect immune homeostasis. However, whether the $H$. illucens larvae as a dietary protein source would benefit mucosal immune responses in the gut remains limited and requires further investigation.

In the present study, we hypothesized that $H$. illucens larvae as a dietary protein source would change the bacterial community and its metabolites, and that these alterations can modulate the immune response in pigs. Therefore, the present study aimed to investigate the effects of $H$. illucens larvae as a dietary protein source on the microbiota, microbial fermentation profile, and mucosal immune responses in the colon of finishing pigs.

\section{Materials and methods}

\section{Preparation of $\boldsymbol{H}$. illucens larvae meal}

$H$. illucens larvae were purchased from Guangzhou AnRuiJie Protection Technology Co., Ltd., (Guangzhou, Guangdong, China). The prepupae were dried at $80^{\circ} \mathrm{C}$ for $30 \mathrm{~min}$ and air dried. Finally, the dried prepupae were crushed to powder through a $1.0-\mathrm{mm}$ opening of a screen and was then used as $H$. illucens larvae meal, and then kept in a well-closed and light-resistant place. The chemical composition, energy content, and amino acid concentration of the $H$. illucens larvae are shown in Table 1.

\section{Animals, diets, and sampling}

A total of 72 crossbred (Duroc $\times$ Landrace $\times$ Large White) female pigs were randomly allocated to three different experimental diets based on their body weights (BW, $76.0 \pm 0.52 \mathrm{~kg}$ ). Pigs in the three treatments received increasing levels of $H$. illucens larvae meal $(0,4 \%$ and $8 \%$; Control, $\mathrm{H} 1$, and $\mathrm{H} 2$ group, respectively). Each treatment consisted of eight pens (replicates), with three pigs per pen. All of the experimental diets were formulated to meet or exceed the nutrient recommendations of the National Research Council (Table 2) [17]. All pigs were provided the diet and water ad libitum during the 46-day experiment. The feed consumption per pen was recorded every day to calculate average daily feed intake (ADFI). The BWs of all pigs were recorded at the beginning and the end of the study period to determine average daily gain (ADG).

At the end of the feeding period (day 46), one pig from each pen was randomly selected and euthanized by electrical stunning and exsanguination after fasting approximately $12 \mathrm{~h}$. The digesta of the colon were collected, homogenized, and stored at $-80^{\circ} \mathrm{C}$ for later determination of the bacterial communities using Illumina MiSeq sequencing and microbial metabolites analyses. A sterile glass microscope slide was used to scrape mucosa as
Table 1 Analyzed chemical characteristics (\% as fed), gross energy ( $\mathrm{MJ} / \mathrm{kg}$ ), and amino acid concentration (\% as fed) of the Hermetia illucens larvae meal used in the present study with finishing pigs

\begin{tabular}{|c|c|}
\hline Items & Hermetia illucens larvae \\
\hline \multicolumn{2}{|l|}{ Analyzed composition } \\
\hline $\mathrm{DM}, \%$ & 92.22 \\
\hline Gross energy, MJ/kg & 21.80 \\
\hline$C P, \%$ & 34.97 \\
\hline Ether extract, \% & 35.49 \\
\hline Ash, \% & 6.46 \\
\hline$A D F, \%$ & 6.71 \\
\hline ADF-linked protein, $\%$ & 5.59 \\
\hline Chitin, \% & 4.65 \\
\hline \multicolumn{2}{|l|}{ Mineral composition, \% } \\
\hline Total P & 0.83 \\
\hline $\mathrm{Ca}$ & 4.39 \\
\hline \multicolumn{2}{|l|}{ Essential amino acids } \\
\hline Lysine & 2.10 \\
\hline Methionine & 0.50 \\
\hline Methionine + Cystine & 0.62 \\
\hline Isoleucine & 1.36 \\
\hline Leucine & 2.12 \\
\hline Tryptophan & 0.60 \\
\hline Valine & 1.86 \\
\hline Threonine & 1.17 \\
\hline Arginine & 2.30 \\
\hline Phenylalanine & 1.18 \\
\hline Histidine & 0.80 \\
\hline \multicolumn{2}{|l|}{ Non-essential amino acids } \\
\hline Alanine & 2.55 \\
\hline Aspartate & 2.67 \\
\hline Glutamate & 4.11 \\
\hline Glycine & 1.61 \\
\hline Serine & 1.16 \\
\hline Tyrosine & 1.63 \\
\hline
\end{tabular}

previously described [18], immediately frozen in liquid nitrogen for later gene expression.

\section{Chemical composition analysis}

The common nutritional components (dry matter, DM; crude protein, CP; crude fat; ash; and acid detergent fiber, ADF) in the experimental diets and H. illucens larvae were analyzed according to the Association of Official Analytical Chemists (AOAC) procedures [16]. To determine the amino acid concentrations in $H$. illucens larvae meal (except methionine and tryptophan), approximately $1.0 \mathrm{~g}$ of each sample was digested in $10 \mathrm{~mL}$ of 6 
Table 2 Feed ingredient and nutrient composition of experimental diets (as-fed basis)

\begin{tabular}{|c|c|c|c|}
\hline \multirow[t]{2}{*}{ Items } & \multicolumn{3}{|c|}{ Treatment $^{\mathrm{a}}$} \\
\hline & Control & $\mathrm{H} 1$ & $\mathrm{H} 2$ \\
\hline \multicolumn{4}{|l|}{ Ingredient, \% } \\
\hline Corn & 71.00 & 71.20 & 71.76 \\
\hline Soybean meal & 16.98 & 13.86 & 10.75 \\
\hline Wheat bran & 6.00 & 6.00 & 6.00 \\
\hline Hermetia illucens L. & - & 4.00 & 8.00 \\
\hline Soybean oil & 2.50 & 1.70 & 0.50 \\
\hline Vitamin-mineral premix ${ }^{b}$ & 1.00 & 1.00 & 1.00 \\
\hline Dicalcium phosphate & 0.95 & 0.95 & 1.00 \\
\hline Limestone & 0.75 & 0.40 & 0.03 \\
\hline $\mathrm{NaCl}$ & 0.30 & 0.30 & 0.30 \\
\hline L-Lysine HCI(98\%) & 0.38 & 0.40 & 0.42 \\
\hline DL-Methionine & 0.06 & 0.07 & 0.09 \\
\hline L-Threonine & 0.06 & 0.11 & 0.15 \\
\hline L-Tryptophan & 0.02 & 0.01 & - \\
\hline Total & 100.00 & 100.00 & 100.00 \\
\hline \multicolumn{4}{|l|}{ Calculated content ${ }^{c}$} \\
\hline$M E^{\mathrm{d}}, \mathrm{MJ} / \mathrm{kg}$ & 14.37 & 14.38 & 14.38 \\
\hline \multicolumn{4}{|c|}{ Standard ileal digestible amino acid, \% } \\
\hline Lysine & 0.73 & 0.73 & 0.73 \\
\hline Threonine & 0.46 & 0.46 & 0.46 \\
\hline Methionine + Cysteine & 0.42 & 0.42 & 0.42 \\
\hline Tryptophan & 0.14 & 0.14 & 0.14 \\
\hline \multicolumn{4}{|c|}{ Analyzed nutrient composition ${ }^{\mathrm{e}}$} \\
\hline Dry matter, \% & 89.22 & 89.16 & 89.23 \\
\hline Crude protein, \% & 14.53 & 14.53 & 14.54 \\
\hline Ether extract, \% & 5.10 & 5.10 & 5.10 \\
\hline Crude ash, \% & 4.36 & 4.39 & 4.50 \\
\hline$A D F, \%$ & 3.51 & 4.50 & 4.92 \\
\hline ADF-linked protein, $\%$ & 0.85 & 1.58 & 2.89 \\
\hline Chitin, \% & 0.00 & 0.90 & 1.90 \\
\hline
\end{tabular}

${ }^{a}$ diets $\mathrm{H} 1$ and $\mathrm{H} 2$ contained $4 \%$ and $8 \%$ Hermetia illucens larvae in an amount providing similar nitrogen to the diet as control diet, respectively

Provided per kilogram of complete diet: vitamin $A, 15,000$ IU; vitamin $D_{3}$, $3,000 \mathrm{lU}$; vitamin $\mathrm{E}, 150 \mathrm{mg}$; vitamin $\mathrm{K}_{3}, 3 \mathrm{mg}$; vitamin $\mathrm{B}_{1}, 3 \mathrm{mg}$; vitamin $\mathrm{B}_{2}, 6$ mg; vitamin $\mathrm{B}_{6}, 5 \mathrm{mg}$; vitamin $\mathrm{B}_{12}, 0.03 \mathrm{mg}$; niacin, $45 \mathrm{mg}$; vitamin $\mathrm{C}, 250 \mathrm{mg}$; calcium pantothenate, $9 \mathrm{mg}$; folic acid, $1 \mathrm{mg}$; biotin, $0.3 \mathrm{mg}$; choline chloride, $500 \mathrm{mg} ; \mathrm{Fe}\left(\mathrm{FeSO}_{4} \cdot \mathrm{H}_{2} \mathrm{O}\right), 170 \mathrm{mg}$; Cu $\left(\mathrm{CuSO}_{4} .5 \mathrm{H}_{2} \mathrm{O}\right), 150 \mathrm{mg}$; I (KI), $0.90 \mathrm{mg} ; \mathrm{Se}$ $\left(\mathrm{Na}_{2} \mathrm{SeO}_{3}\right), 0.2 \mathrm{mg} ; \mathrm{Zn}\left(\mathrm{ZnSO}_{4} \cdot \mathrm{H}_{2} \mathrm{O}\right), 150 \mathrm{mg} ; \mathrm{Mg}(\mathrm{MgO}), 68 \mathrm{mg} ; \mathrm{Mn}$

$\left(\mathrm{MnSO}_{4} \cdot \mathrm{H}_{2} \mathrm{O}\right), 80 \mathrm{mg} ; \mathrm{Co}\left(\mathrm{CoCl}_{2}\right), 0.3 \mathrm{mg}$

'Values were based on the chemical analysis

${ }^{\mathrm{d}} \mathrm{ME}=$ metabolized energy

${ }^{\mathrm{e}}$ Analytical results obtained according to AOAC [16]

$\mathrm{mol} / \mathrm{L} \mathrm{HCl}$ at $110^{\circ} \mathrm{C}$ for $24 \mathrm{~h}$; the methionine concentration was measured after oxidation with performic acid, and tryptophan concentrations were determined after alkaline hydrolysis according to the AOAC [16]. The protein linked to $\mathrm{ADF}$ in the experimental diets and $H$. illucens larvae were determined [19], and used to estimate the amount of chitin according to previous study [20].

Colonic SCFAs concentrations were determined by gas chromatography (GC) according to a previous study [21]. Lactate concentration in the colonic digesta was measured using a commercial assay kit (Nanjing Jiancheng Biological Engineering Institute, Nanjing, China) according to the manufacturer's instructions. Ammonia concentration in the colonic digesta was measured using UV spectrophotometer according to a previous method [22]. The biogenic amines concentrations in the colonic digesta were analyzed using high-performance liquid chromatography (HPLC) with precolumn dansylation according to a previous study [23]. The concentrations of phenolic and indolic compounds were analyzed by HPLC, as described previously [24], with slight modifications. Briefly, $0.1 \mathrm{~g}$ of the colonic digesta was mixed with $1.0 \mathrm{~mL}$ acetonitrile. The mixture was vortexed and stored at $-20^{\circ} \mathrm{C}$ for $20 \mathrm{~min}$ and then centrifuged at $3,000 \times g$ for $10 \mathrm{~min}$ at $4{ }^{\circ} \mathrm{C}$. The supernatant was filtered through a $0.22-\mu \mathrm{m}$ membrane and then analyzed on a Waters Alliance system (Alliance HPLC System e2695 separation module; Waters, Milford, MA, USA) with a multi $\lambda$ fluorescence detector (Waters 2475). Gradient elution of two mobile phases was used: mobile phase A consisted of HPLC grade water, and mobile phase B was acetonitrile. The gradient program was: $82 \%$ A initially, $55 \% \mathrm{~A}$ at $12 \mathrm{~min}, 10 \% \mathrm{~A}$ at $22 \mathrm{~min}$, and $100 \% \mathrm{~B}$ at 23 min. The flow rate was $1.0 \mathrm{~mL} / \mathrm{min}$, and column temperature was $30^{\circ} \mathrm{C}$.

\section{DNA extraction, Illumina MiSeq sequencing, and data processing}

Total genomic DNA in the colonic digesta was extracted using the QIAamp PowerFecal DNA Kit (QIAGEN, Hilden, Germany), according to the manufacturer's instructions. DNA concentrations of all samples were quantified with the Nanodrop 1000 spectrophotometer (Thermo Fisher Scientific Inc., Wilmington, DE, USA). The V3-V4 regions of all bacterial 16S rRNA genes were amplified by polymerase chain reaction (PCR) using the $338 \mathrm{~F}$ universal forward primer (5'-ACTCCTRCGGGAGGCAGCAG-3') and the 806R universal reverse primer (5'-GGAC TACCVGGGTATCTAAT-3') [25]. The PCR products were purified using the AxyPrep DNA Gel Extraction Kit (Axygen Biosciences, Union City, CA, USA), according to the manufacturer's instructions. The purified amplicons were pooled in equimolar concentrations from each sample and paired-end sequenced $(2 \times 250)$ on an Illumina MiSeq platform (Majorbio, Shanghai, China) according to standard protocols [26].

The raw sequence data generated from 16S rRNA MiSeq sequencing were demultiplexed and quality-filtered using the QIIME (version 1.17) software package [27]. 
Gaps in each sequence were discarded from all samples to decrease noise by screening, filtering, and pre-clustering processes as described by a previous study [28]. Operational taxonomic units (OTUs) were clustered with a cut-off of value 97\% similarity using UPARSE (version 7.1, http://drive5.com/uparse/), and chimeric sequences were identified and removed using UCHIME [29]. The representative sequence of each OTU was analyzed with the Ribosomal Database Project Classifier (RRID: SCR_006633) against the Silva (SSU119) 16S rRNA database at a confidence level of $90 \%$.

Bacterial diversity, including a rarefaction analysis, richness estimators (Chao 1 and ACE), and diversity indices (Shannon and Simpson) were calculated using MOTHUR software (version 1.35.1, http://www.mothur. org), according to previous instructions [30]. The principal coordinate analysis (PCoA) was performed based on the Bray-Curtis distance, and analysis of molecular variance (AMOVA) was performed to compare the dissimilarities among the specimens [30].

The $16 \mathrm{~S}$ sequencing data in this study were deposited in the National Center of Biotechnology Information (NCBI) Sequence Read Archive (SRA) database under accession number PRJNA504488.

\section{Quantitative real-time PCR}

The quantities of total bacteria, Firmicutes, Ruminococcus, Bacteroides-Prevotella, Clostridium cluster IV, Clostridium cluster XIVa, Bifidobacterium, Escherichia coli and Lactobacillus from each sample of colonic digesta $(n=8)$ were quantified by real-time quantitative PCR (qPCR) using specific primers (Additional file 1: Table S1). qPCR was performed on the CFX96 Real-Time PCR Detection System (Bio-Rad, Hercules, CA, USA) with TB Green ${ }^{\text {Tx }}$ Premix Ex Taq ${ }^{\text {mi }}$ (Takara Biotechnology, Dalian, China). The reaction mixtures and qPCR conditions were set according to a previous study [21].

\section{Mucosal RNA extraction of colon and real-time PCR}

Total RNA was extracted from the colonic mucosa with the TRIzol reagent (Takara Biotechnology, Dalian, China) according to the manufacturer's instructions. The RNA quality of every sample was quantified by Nanodrop 1000 spectrophotometer (Thermo Fisher Scientific Inc., Wiington, $\mathrm{DE}, \mathrm{USA})$, and the ratio $\left(\mathrm{OD}_{260}: \mathrm{OD}_{280}\right)$ ranged from 1.8 to 2.0. Thereafter, $1 \mu \mathrm{g}$ total RNA was reverse-transcribed to cDNA using a Synthesis Kit (Takara Biotechnology, Dalian, China) according to the manufacturer's instructions. Primers used for selected genes were presented in Additional file 2: Table S2 in the supplemental material. Real-time PCR of the target genes and $\beta$-actin was performed on CFX96 Real-Time PCR Detection System (Bio-Rad, Hercules, CA, USA) with TB Green ${ }^{\text {Tx }}$ Premix Ex Taq (Takara Biotechnology, Dalian, China). The reaction mixtures and real-time PCR conditions were set according to a previous study [18]. The housekeeping gene $\beta$-actin was used to normalize the expression levels of each target gene, and according to the following formula $2^{-(\Delta \Delta \mathrm{Ct})}$, where $\Delta \Delta \mathrm{Ct}=\left(\mathrm{Ct}_{\text {target }}-\mathrm{Ct}_{\beta \text {-actin }}\right)_{\text {treatment }}-$ $\left(\mathrm{Ct}_{\text {target }}-\mathrm{Ct}_{\beta \text {-actin }}\right)_{\text {control }}$.

\section{Data analysis}

All experimental data were analyzed using the SPSS software package (SPSS v. 20.0, SPSS Inc., Chicago IL, USA). The normality of the data distribution was confirmed by the Shapiro-Wilk test before assessing differences between the groups. The Kruskal-Wallis One-way analysis of variance (ANOVA) with the Benjamini-Hochberg false discovery rate (FDR) multiple-testing correction [31] was used to analyze non-normally distributed variables (some taxa richness data). Bacterial abundance data (at the phylum, genus, and species levels) are expressed as medians; a $P$-value $<0.05$ was regarded as significant.

The bacterial gene copy, metabolite concentration (lactate, SCFAs, ammonia, amines, and phenol and indole compounds), and gene expression data that were normally distributed were analyzed by One-way ANOVA with a Tukey's post hoc test. Data are expressed as means \pm standard error of mean (SEM), and $P \leq 0.05$ was regarded as significant. Correlations between mucosal gene expression and significantly changed bacterial abundances (at the genus level and qPCR, $q<0.05$ ) and fermentation end-products by dietary treatment were analyzed by Spearman's correlation analysis using GraphPad Prim version 5.0 (GraphPad Software, San Diego, CA, USA). A correlation was considered significant when the absolute Spearman's correlation coefficient was $>0.5$ and significant at $P<0.05$.

\section{Results}

\section{Growth performance}

During the whole trial, the pigs were considered healthy and no mortality has been observed. In this study, the H1 diet significantly increased $(P<0.05)$ the ADG of pigs (means \pm SEM: $0.89 \pm 0.03 \mathrm{~kg} / \mathrm{d}, 0.98 \pm 0.03 \mathrm{~kg} / \mathrm{d}$, $0.86 \pm 0.02 \mathrm{~kg} / \mathrm{d}$ in control, $\mathrm{H} 1$, and $\mathrm{H} 2$ group, respectively) and decreased $(P<0.05)$ the feed conversion rate (F:G) $(3.21 \pm 0.06,2.85 \pm 0.12,3.23 \pm 0.05$ in control, H1, and $\mathrm{H} 2$ group, respectively) compared with control and $\mathrm{H} 2$ diets. However, no difference in the ADFI (One-way ANOVA, $P=0.466)$ was observed between the control group (means \pm SEM: $2.83 \pm 0.05 \mathrm{~kg} / \mathrm{d}$ ), H1 group (means \pm SEM: $2.77 \pm 0.03 \mathrm{~kg} / \mathrm{d}$ ), and $\mathrm{H} 2$ group (means \pm SEM: $2.87 \pm 0.04 \mathrm{~kg} / \mathrm{d}$ ).

\section{Microbiota composition of the colonic digesta}

The microbial composition of the colonic digesta following the $H$. illucens larvae treatment was revealed 
by $16 \mathrm{~S}$ rRNA Illumina MiSeq sequencing. In the present study, a total of 1,031,156 V3-V4 16S rRNA effective sequences from the 24 samples, with an average 42,954 sequences per sample, were used for subsequent analysis. The flattened rarefaction curves showed that the sampling in each group provided sufficient OTU coverage (Additional file 3: Figure S1). No significant differences in species richness (as reflected by the $\mathrm{ACE}$ and Chao1 indices) or diversity (as reflected by Shannon and Simpson indices) were observed in the colonic digesta bacteria at the taxonomic level (Fig. 1a). However, the PCoA with the Bray-Curtis distance results showed that the H1 group was separated from the control group (Fig. 1b). AMOVA analysis also showed significant dissimilarities between the $\mathrm{H} 1$ and control groups $(F \mathrm{~s}=2.25$, $P<0.01$, among control, $\mathrm{H} 1$, and $\mathrm{H} 2$ groups; $F \mathrm{~s}=$ 1.63, $P<0.05, \mathrm{H} 1$ vs. $\mathrm{H} 2 ; F \mathrm{~s}=3.45, P<0.001$, control vs. $\mathrm{H} 1 ; F \mathrm{~s}=1.61, P=0.069$, control vs. $\mathrm{H} 2$ ).

At the phylum level, the Firmicutes and Bacteroidetes were the two dominant phyla, contributing $74.99 \%$ and $22.09 \%$ to the control group, $75.75 \%$ and $21.40 \%$ to the $\mathrm{H} 1$ group, and $78.54 \%$ and $17.93 \%$ to the $\mathrm{H} 2$ group, respectively (Fig. 1c). Proteobacteria and Actinobacteria were the next two most dominant phyla, accounting for $1.78 \%$ and $0.19 \%$ in the control group, $1.69 \%$ and $0.55 \%$ in the $\mathrm{H} 1$ group, $2.17 \%$ and $0.66 \%$ in the $\mathrm{H} 2$ group, respectively. No significant changes were found in the abundances of any of the phyla.

At the genus level, the 30 most predominant genera in the colonic digesta are presented as a heat map (Additional file 4: Figure S2). The 10 most predominant genera (those with a relative abundance $\geq 3 \%$ in at least one treatment) were Lactobacillus, Streptococcus, unclassified Ruminococcaceae, unclassified Lachnospiraceae, Clostridium_sensu_stricto_1, unclassified Prevotellaceae, unclassified S24-7, Prevotella, unclassified Peptostreptococcaceae, and unclassified Christensenellaceae. The relative abundance of Lactobacillus, Pseudobutyrivibrio, Roseburia, Oribacterium, and Faecalibacterium increased significantly in pigs fed the $\mathrm{H} 1$ diet $(P<0.05)$ compared with control diet, but the abundance of Streptococcus decreased $(P<0.05)$ (Fig. 2a). Meanwhile, the $\mathrm{H} 1$ diet resulted in a higher abundance of Peptococcus than that of the $\mathrm{H} 2$ diet $(P<0.05)$.

At the species level, a total of 1505 OTUs was identified in the colonic digesta. As shown in Fig. 2b, the relative abundance of OTUs closely related to Streptococcus pasteurianus, Streptococcus gallolyticus, Treponema sp., Ruminococcus sp., Clostridium sp., Kineothrix alysoides, Oscillibacter sp., Clostridium asparagiforme, Eubacterium sp., Prevotella sp., and Barnesiella sp. (Fig. 2b) significantly decreased in pigs fed the $\mathrm{H} 1$ diet $(P<0.05)$ compared with the control diet, while the relative abundance of OTUs closely related to Lactobacillus johnsonii and Lactobacillus sp. increased $(P<0.05)$. Meanwhile, the $\mathrm{H} 1$ diet also increased $(P<0.05)$ the abundance of OTU closely related to Peptococcus sp. compared with the $\mathrm{H} 2$ diet.

Some key bacteria groups were determined by qPCR to identify the quantitative changes in the bacterial groups in the colonic digesta following treatment with $H$. illucens larvae. As shown in Fig. 3, the H1 diet significantly increased $(P<0.05)$ the numbers of Lactobacillus, Clostridium cluster IV, and Roseburia compared with the control diet. The H2 diet also increased $(P<0.05)$ the number of Clostridium cluster IV compared with the control diet. However, no significant differences $(P>0.05)$ were observed in the numbers of total bacteria, Firmicutes, Bacteroidetes, Ruminococcus, Prevotella, Clostridium cluster XIVa, E. coli, or Bifidobacterium among the different dietary treatments. Taken together, these results indicate that a diet including $4 \% \mathrm{H}$. illucens larvae meal significantly changed the colonic digesta bacterial community structure.

\section{Fermentation metabolites in the colonic digesta}

To explore whether feeding $H$. illucens larvae affects the fermentation profile of the colonic digesta, some microbial metabolites were determined. For SCFAs (Fig. 4b), the concentrations of total SCFAs, butyrate, and isobutyrate increased significantly in pigs fed the $\mathrm{H} 1$ diet $(P<$ $0.05)$ compared with the control diet. The concentration of butyrate also increased $(P<0.05)$ in response to the $\mathrm{H} 2$ diet compared with the control diet. However, the dietary treatment did not affect the acetate, propionate, branch-chain fatty acid (BCFA), valerate, or isovalerate concentrations $(P>0.05)$. The concentration of lactate in the colonic digesta was not affected by the dietary treatments (Fig. 4a).

Biogenic amines and ammonia are produced from bacterial decarboxylation and deamination of amino acids, respectively. For biogenic amines (Fig. 5a), cadaverine, putrescine, and tryptamine were the major biogenic amines in the colonic digesta. The concentrations of total amines, cadaverine, and tryptamine decreased significantly $(P<0.05)$ in pigs fed the $\mathrm{H} 1$ diet compared with the control diet, as well as the concentration of total amines decreased $(P<0.05)$ compared with the $\mathrm{H} 2$ diet. However, the concentrations of putrescine, spermine, methylamine, tyramine, and spermidine were not affected by the different dietary treatments $(P>0.05)$. The dietary treatments also did not affect the ammonia concentration (Fig. 5b).

Phenol and indole compounds are derived from metabolism of aromatic amino acids by intestinal bacteria. As shown in Fig. $5 \mathrm{c}$, the $\mathrm{H} 1$ and $\mathrm{H} 2$ diets significantly decreased $(P<0.05)$ the concentrations of phenol, $p$-cresol, and skatole compared with the control diet. However, the concentration of indole was not affected by the different 


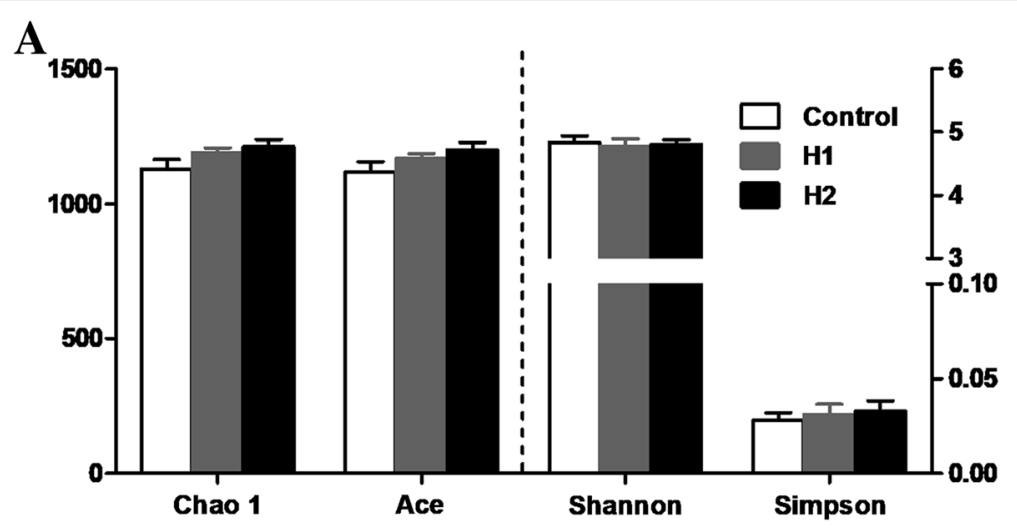

$\mathbf{B}$

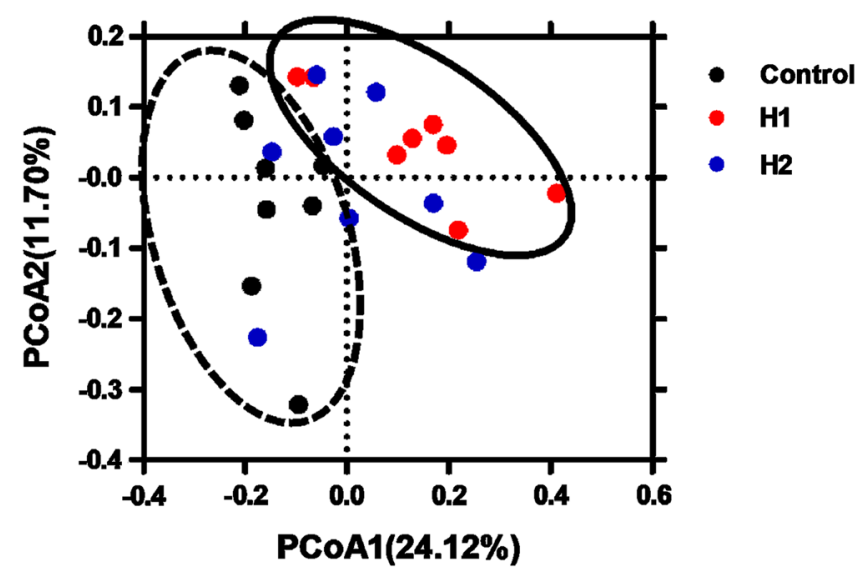

$\mathbf{C}$

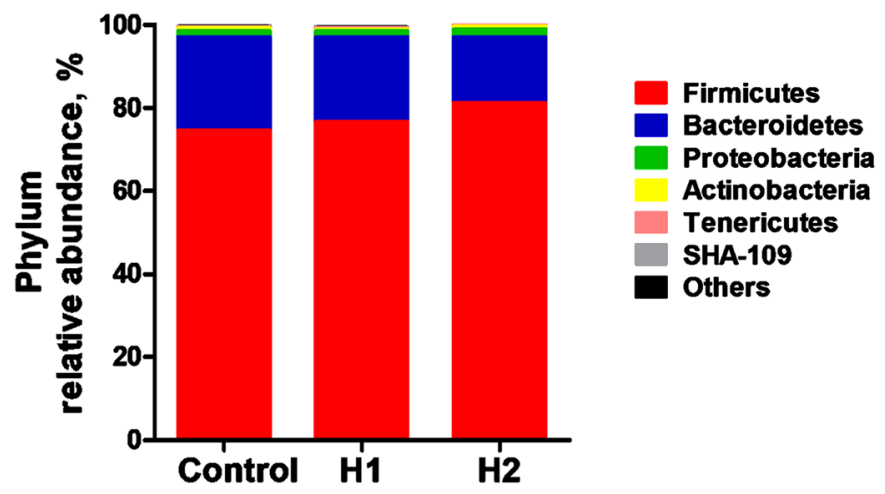

Fig. 1 a Diversity and richness of colonic digesta microbial community at the $3 \%$ dissimilarity level. The values are means \pm SEM $(n=8)$. $\mathbf{b}$ Principal coordinates analysis (PCOA) of bacterial communities in the colonic digesta of pigs (based on the Bray-Curtis distance). Circles with dash line or solid indicate that groups were significantly distinct using AMOVA analysis $(P<0.05)$. c Phylum-level relative abundance of 165 rRNA gene sequences from the colonoc digesta of pigs

dietary treatments $(P>0.05)$. Overall, these results indicate that a diet including $H$. illucens larvae markedly increased the concentrations of SCFAs (total SCFAs, butyrate, and isobutyrate), but decreased the concentrations of biogenic amines as well as phenol and indole compounds in the colonic digesta, suggesting a strong impact of $H$. illucens larvae on carbohydrate and amino acid metabolism characteristics in the colon.
Gene expression in colonic mucosa

To assess whether feeding $H$. illucens larvae affects the intestinal immune function, the mRNA expression of several TLR, cytokines, and tight junction proteins were determined. As shown in Fig. 6, the H1 diet significantly down-regulated the relative mRNA expression of TLR-4 and IFN- $\gamma$ compared with control diet $(P<0.05)$, while up-regulated the relative mRNA expression of $I L-10$, 


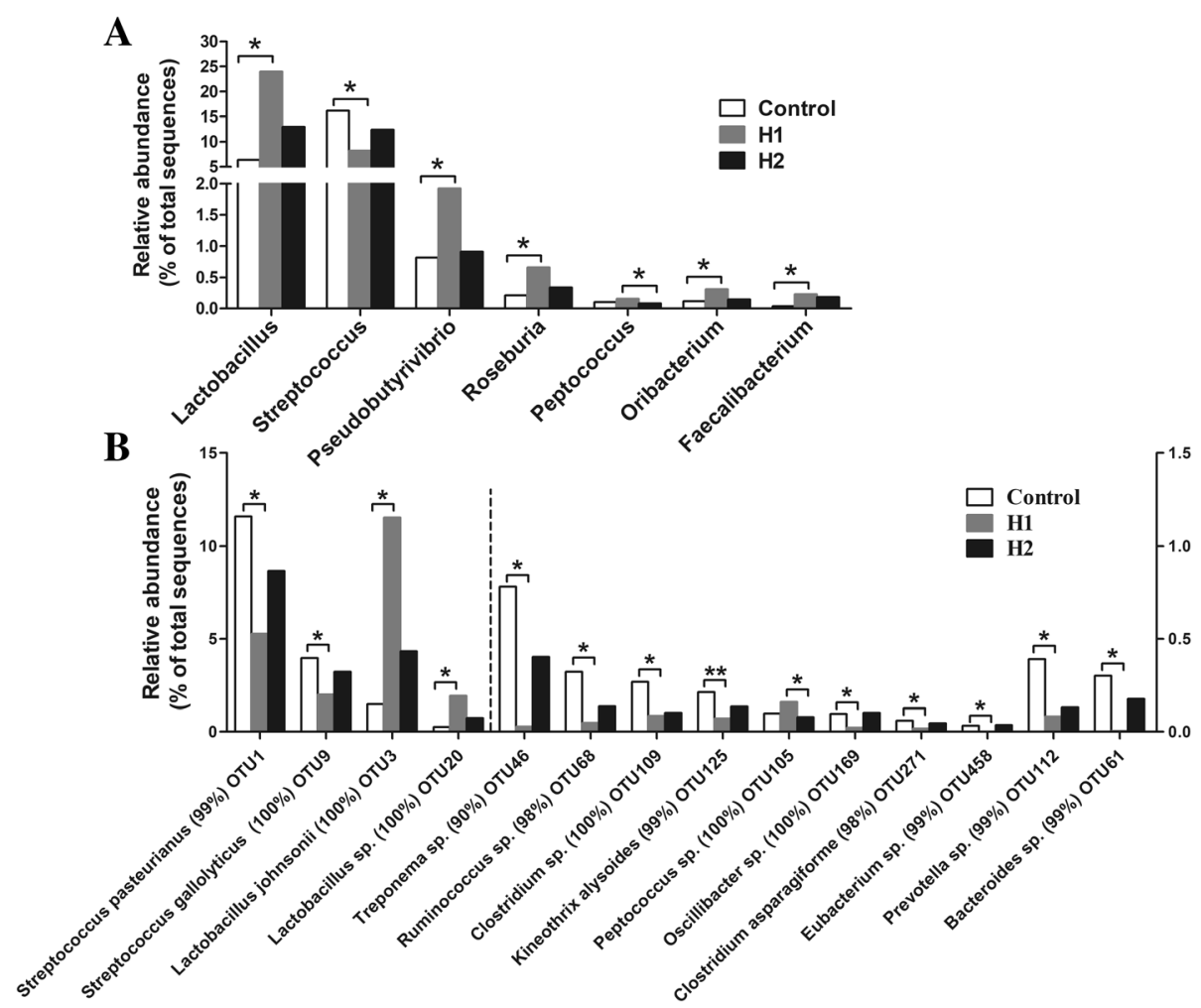

Fig. 2 Significantly changed bacteria genera (a) and species (b) by Hermetia illucens larvae treatments. The values were expressed as the medians $(n=8)$. Asterisks indicated statistical differences between different group (Kruskal-Wallis test): ${ }^{*}$ FDR-adjusted $P$-value $<0.05$; ${ }^{*}$ FDR-adjusted $P$ value $<0.01$. OTU, operational taxonomic unit

ZO-1, occludin, and mucin-1 $(P<0.05)$. The $\mathrm{H} 2$ diet also down-regulated the relative mRNA expression of IFN- $\gamma$ compared with control diet $(P<0.05)$, while up-regulated the relative mRNA expression $Z O-1(P<$ $0.05)$. However, there was no significant difference in the expression of TLR-2, TLR-5, IL-8, TNF- $\alpha$, and mucin-2 among the three groups $(P>0.05)$.

\section{Correlation analysis between mucosal gene expression with colonic microbiome or bacterial fermentation metabolites}

A Spearman's rank correlation analysis matrix was carried out to determine whether there was any relationship among mucosal gene expression and microbial composition (abundance of bacterial genera and

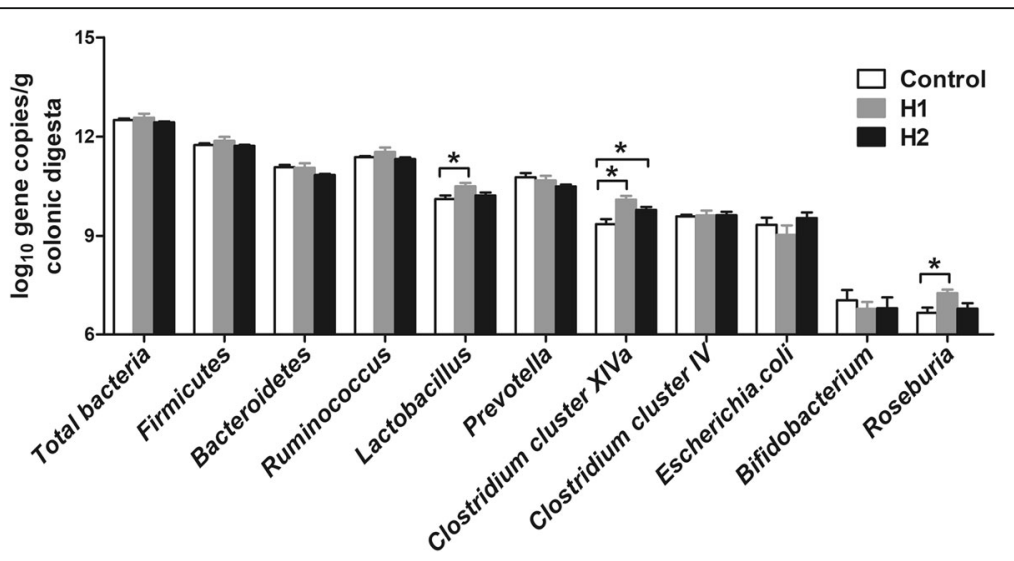

Fig. 3 Response of the copy numbers ( $\log _{10}$ gene copies/g digesta sample) of major bacterial taxonomic groups in the colonic digesta of pigs toward Hermetia illucens larvae treatments. The values are means $\pm \operatorname{SEM}(n=8)$. Asterisks indicated statistical differences between different group (One-way ANOVA with a Tukey post hoc test): ${ }^{*} P<0.05$ 

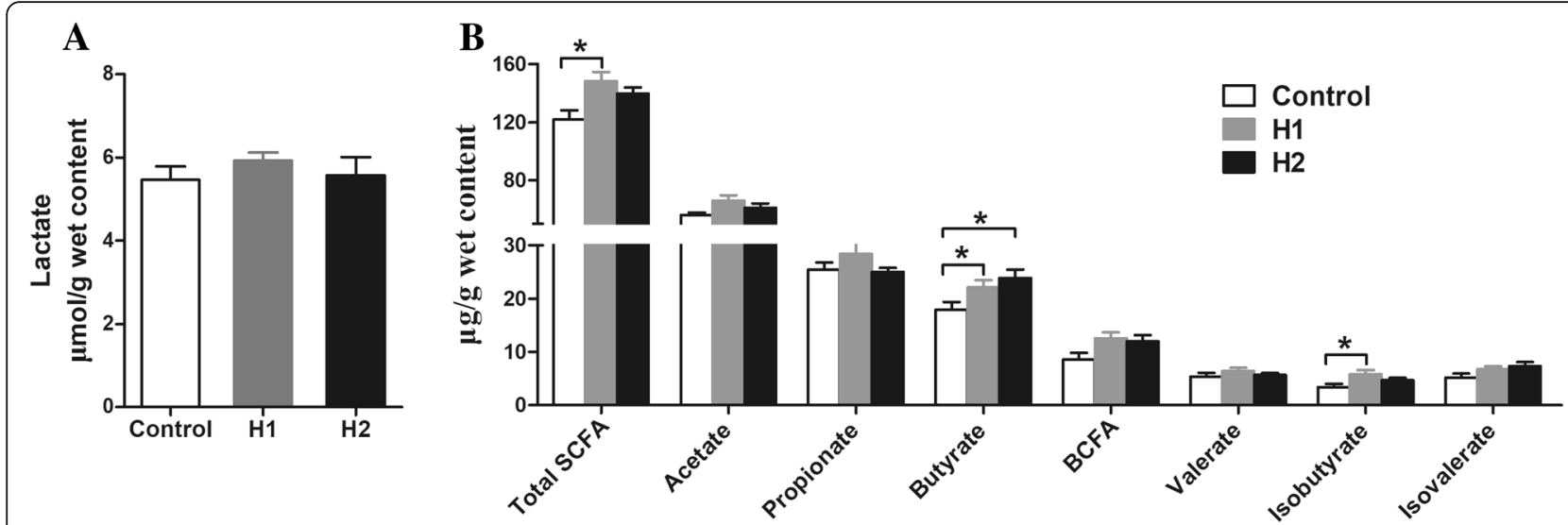

Fig. 4 Effect of the dietary inclusion of Hermetia illucens larvae on the concentration of lactate (a) and short-chain fatty acid (SCFA) (b) in the colonic digesta of pigs. The values are means $\pm \operatorname{SEM}(n=8)$. Asterisks indicated statistical differences between different group (One-way ANOVA with a Tukey post hoc test): ${ }^{*} P<0.05$. Abbreviations: Total SCFA, total short-chain fatty acid; BCFA, branched-chain fatty acid

qPCR results) and the concentrations of metabolites (Fig. 7). The correlation analysis revealed that the mRNA expression level of TLR-4 was positively correlated with Streptococcus, total amines, cadaverine, skatole, and phenol $(P<0.05)$, while negatively correlated with Peptococcus and total SCFA $(P<0.05)$. The
mRNA expression level of IFN- $\gamma$ was positively correlated with Streptococcus, total amines, cadaverine, and phenol $(P<0.05)$, while negatively correlated with Lactobacillus, Pseudobutyrivibrio, Roseburia, Faecalibacterium, Clostridium cluster XIVa, total SCFA, and butyrate $(P<0.05)$. The mRNA expression level of
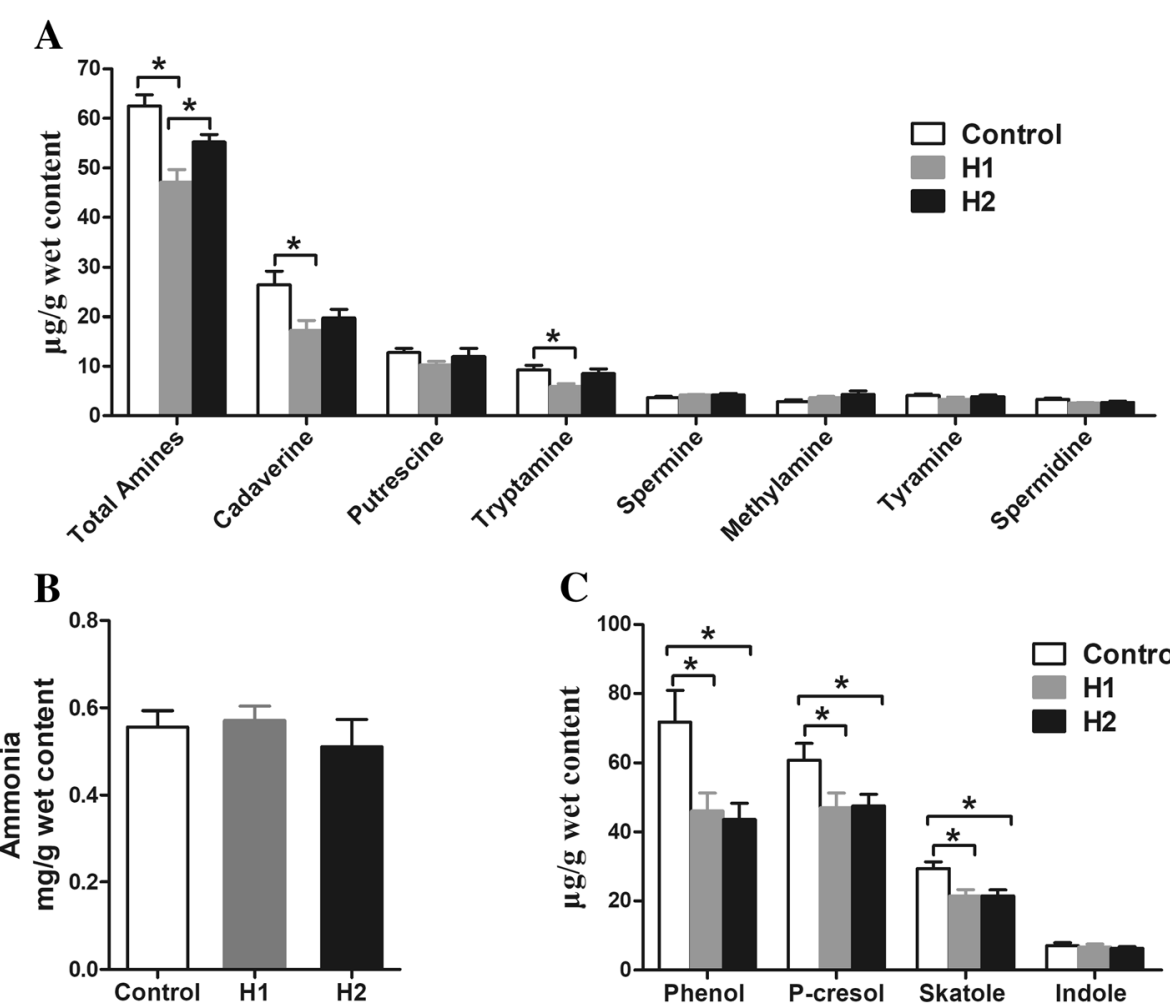

$\mathrm{C}$

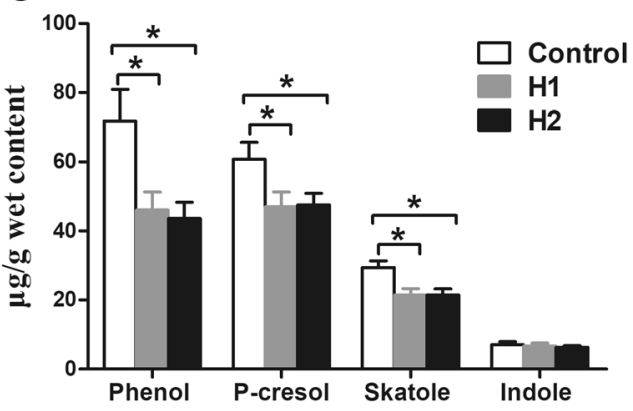

Fig. 5 Effect of the dietary inclusion of Hermetia illucens larvae on the concentration of amino acid fermentation products in the colonic digesta of pigs: biogenic amines (a), ammonia (b), and phenolic and indole compounds (c). The values are means \pm SEM $(n=8)$. Asterisks indicated statistical differences between different group (One-way ANOVA with a Tukey post hoc test): ${ }^{*} P<0.05$ 


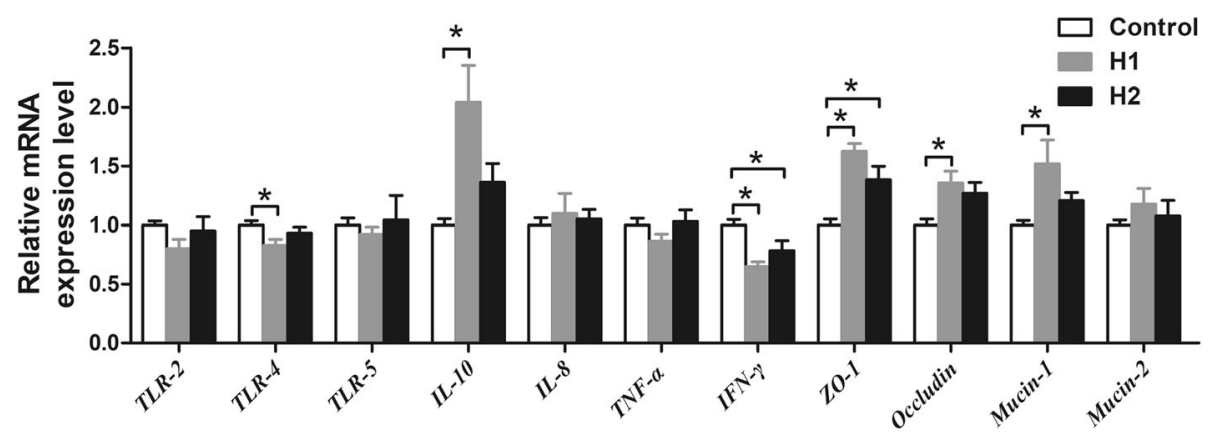

Fig. 6 Effect of the dietary inclusion of Hermetia illucens larvae on the relative mRNA expression of genes related to TLR, cytokines, and barrier function in the colonic mucosa. Asterisks indicated statistical differences between different group (One-way ANOVA with a Tukey post hoc test): $* P<0.05$

IL-10 was positively correlated with Lactobacillus, Peptococcus, Clostridium cluster XIVa, and butyrate $(P<0.05)$, while negatively correlated with Streptococcus, total amines, cadaverine, and phenol $(P<0.05)$. Furthermore, the mRNA expression level of $Z O-1$ showed positive correlations with Pseudobutyrivibrio, Roseburia, Faecalibacterium, Clostridium cluster XIVa, total SCFA, and butyrate $(P<0.05)$, while showed negative correlations with Streptococcus, total amines, cadaverine, skatole, and phenol $(P<0.05)$. The mRNA expression level of occludin was positively correlated with Roseburia and total SCFA $(P<0.05)$, while negatively correlated Streptococcus, total amines, cadaverine, and skatole $(P<0.05)$. The mRNA expression of mucin-1 was positively correlated with
Faecalibacterium, Clostridium cluster XIVa, total SCFA, and butyrate $(P<0.05)$. Additionally, the correlation between bacteria and the concentrations of metabolites were also analyzed and showed in supplementary Additional file 5: Figure S3. Collectively, these results indicate that the changes in the colonic digesta microbiota and metabolites were correlated with alterations of epithelial gene expression in pig.

\section{Discussion}

H. illucens larvae are a novel source of dietary protein that have been used widely in the diets of animals, such as broiler chickens, laying hens, and weaning piglets [2]. The present study, used 16S rRNA Miseq sequencing and biochemical analyses, for the first time to identify

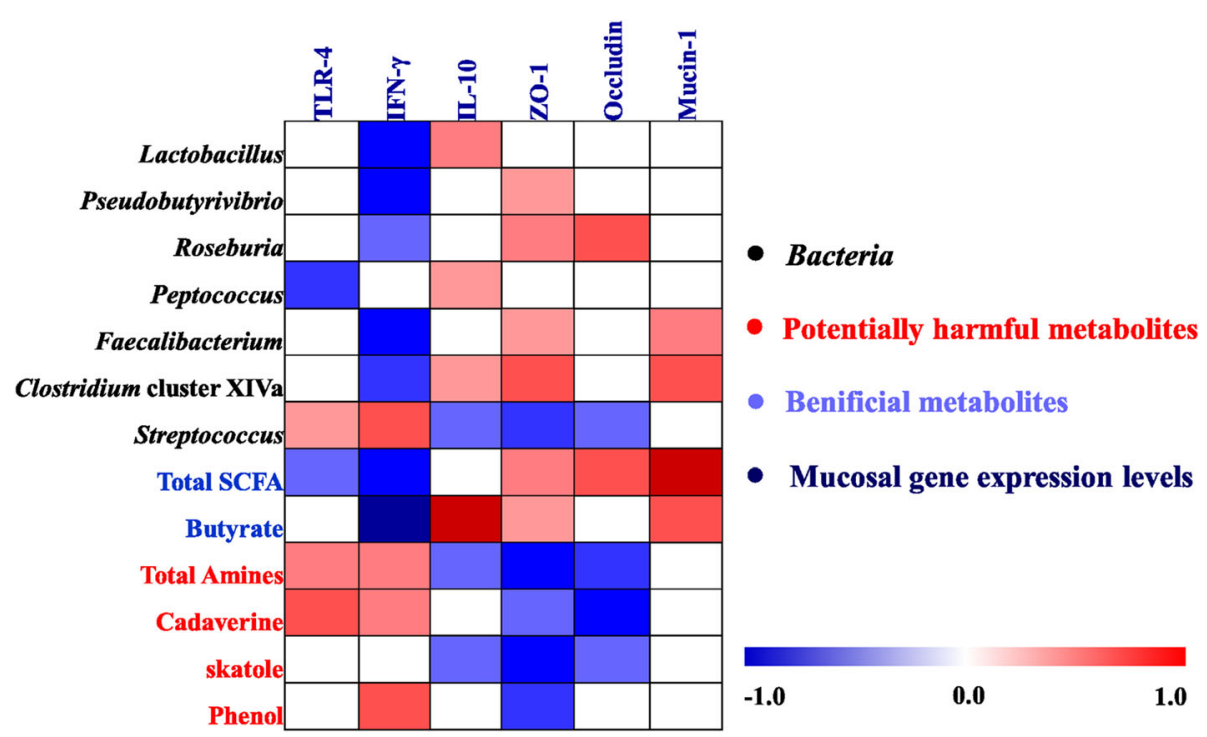

Fig. 7 Spearman's correlation analysis between the abundance of colonic microbiota (at the genus level and gPCR), microbial metabolites and mucosal gene expression level affected by dietary treatment. Cells are colored based on the correlation coefficient between the significantly changed bacteria (the relative abundance and the numbers of bacteria) and metabolites (concentrations) and mucosal gene expression level. The intensity of the colors represents the degree of association. Red represented a significant positive correlation $(P<0.05)$, blue represents significantly negative correlation $(P<0.05)$, and white shows that the correlation was not significant $(P>0.05)$. Total SCFA: total short-chain fatty acids 
the changes in the microbiota and metabolites of the colonic digesta and mucosal immune genes expression in finishing pigs in response to administration of $H$. illucens larvae. Our results showed that dietary supplementation with $4 \% \mathrm{H}$. illucens larvae dramatically increased the abundance and numbers of Lactobacillus and some butyrate-producing bacteria (Pseudobutyrivibrio, Roseburia, and Faecalibacterium), SCFAs concentrations, anti-inflammatory cytokine, and intestinal barrier genes expression in the colon, but decreased the abundance of Streptococcus, the concentrations of nitrogenous fermentation products (cadaverine, tryptamine, phenol, $p$-cresol, and skatole), and pro-inflammatory cytokine genes expression. The changes in the colonic mucosal gene expression were associated with changes in bacterial composition and their metabolites (Fig. 8). These findings suggest that feeding low levels (about 4\%) of $\mathrm{H}$. illucens larvae in the diet may act as a potential prebiotic for finishing pigs.

\section{H. illucens larvae significantly alter the colonic microbiota structure of finishing pigs}

Diet composition is the major factor that affects the gastrointestinal tract microbiota [32]. In the present study, a diet including $4 \% \mathrm{H}$. illucens larvae caused a significant difference in the colonic microbial composition compared with the control group, as revealed by the Bray-Curtis PCoA and AMOVA analyses. The univariate statistical analysis indicated that a $H$. illucens larvae meal (in $4 \%$ supplementation) markedly increased the abundance of many potentially beneficial bacteria and reduced the abundance of potentially opportunistic pathogens compared with control diet. Among the genera affected by the $H$. illucens larvae, bacterial species, such as Lactobacillus markedly increased in the $\mathrm{H} 1$ pigs (Fig. 2a). The H. illucens larvae treatment also increased the numbers of Lactobacillus in laying hens by an average of 7.44-fold [10]. Lactobacillus mainly exerts health-promoting effects on gut physiology and is generally considered a potentially beneficial microbe. Thus, these results suggest that $H$. illucens larvae increased the potentially beneficial bacteria. Meanwhile, $H$. illucens larvae also increased some butyrate-producing bacteria, such as Roseburia, Pseudobutyrivibrio, and Faecalibacterium in the colon (Fig. 2a). Some species within the genera Roseburia, Pseudobutyrivibrio, and Faecalibacterium together with butyrate, are essential for maintaining the intestinal metabolism [33], and have many beneficial effects for colonic homeostasis by promoting epithelial energy metabolism and stimulating immune development [34]. In addition, another important finding was that $H$. illucens larvae significantly increased the number of Clostridium cluster XIVa bacteria (Fig. 3). Bacteria within Clostridium cluster XIVa are regarded as a predominant population and are butyrate producers [35]. which play a crucial role in maintaining gut health. Therefore, the increase in the abundance of Roseburia, Pseudobutyrivibrio, and Faecalibacterium and the number of Clostridium cluster XIVa in the colon indicate that carbohydrate metabolism by bacteria may have been affected by administration $H$. illucens larvae.

On the other hand, diet including 4\% H. illucens larvae markedly decreased the abundance of Streptococcus compared with the control diet (Fig. 2a). Some bacteria within the genus Streptococcus, including S. gallolyticus [36] and S. pasteurianus [37] are opportunistic

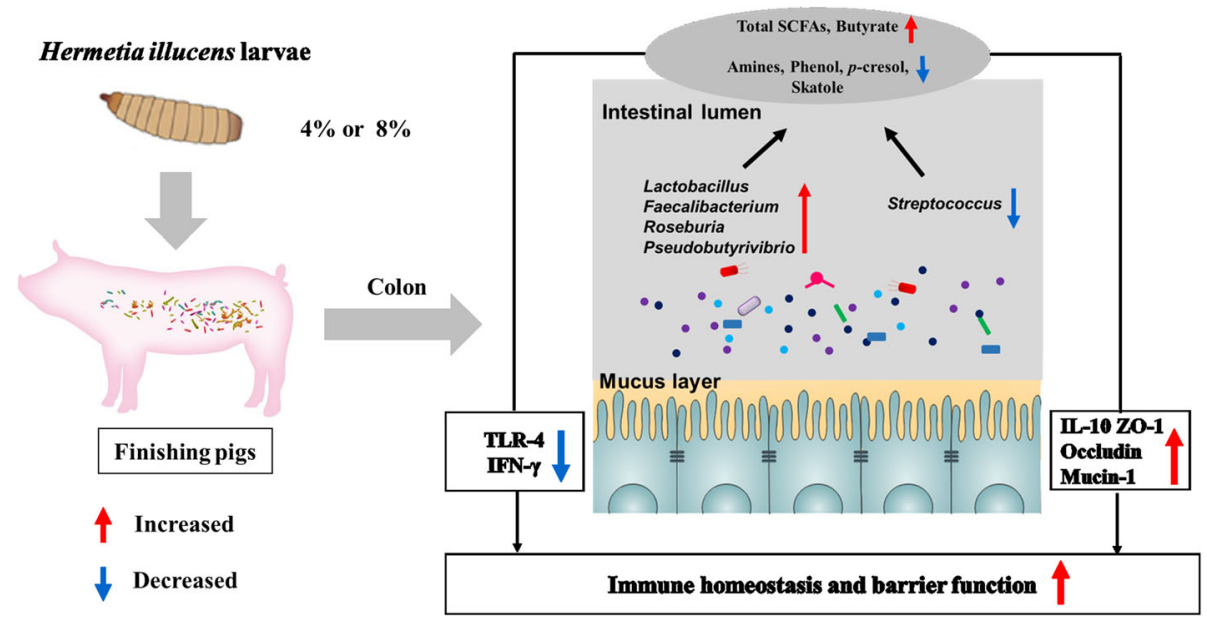

Fig. 8 Proposed function model of Hermetia illucens larvae meal. Items with blue down-arrow indicated the decreased bacteria, metabolites, or genes expression in the Hermetia illucens larvae diet group compared with the control diet, whereas those with a red up-arrow indicated the decreased ones in the Hermetia illucens larvae diet group. Total SCFAs: total short-chain fatty acids; IFN- $\gamma$ : interferon- $\gamma$; IL-10: interleukin-10; TLR-4: Toll-like receptors-4; TNF-a, tumor necrosis factor-a; ZO-1: Zona occludens protein 1 
pathogens that induce diarrhea in pigs or are associated with digestive tract malignancies, respectively. An increase in the abundance of Streptococcus has been reported in the feces of patients with colorectal cancer [38]. Thus, the decrease in the abundance of Streptococcus suggests that the dietary inclusion of $4 \% \mathrm{H}$. illucens larvae may have beneficial to intestinal health for finishing pigs.

Until now, the exact mechanism for the change in the colonic microbiota by $H$. illucens larvae has remained unclear. H. illucens larvae contain chitin (about $4.65 \%$ in the present study), which serves as a substrate for gut microbiota and then alters their composition. Previous studies have indicated that low-level chitin restores the compositional balance in the microbial communities of humans [39] or mice [40]. H. illucens larvae also have a high concentration of the medium-chain fatty acid (MCFA) lauric acid (C12:0, about $28 \%$ of total fatty acids in the present study, unpublished data), which is a natural antimicrobial agent and particularly active against Gram-positive bacteria [41, 42]. Furthermore, $H$. illucens larvae are also a potential source of antimicrobial peptides (AMP) and have broad-spectrum activity against both Gram-positive and Gram-negative bacteria [43]. Therefore, administering $H$. illucens larvae regulates the microbiota in the colon probably through chitin, lauric acid, and/or AMPs, but should be further studied to clarify the underlying mechanisms.

Additionally, we found that dietary inclusion of $8 \%$ H. illucens did not result in beneficial effects on the colonic microbiota in the current trial. To the best of our knowledge, the current study is the first to test partially $H$. illucens larvae inclusion in the diets of finishing pigs. Therefore, the available information on the effect of dietary $H$. illucens larvae inclusion on gut microbiota of finishing pigs is very limited. As mentioned above, $H$. illucens larvae contain chitin, which is not digestible by monogastric animals. A previous study has indicated that low concentrations of chitin might increase the number of Lactobacillus and decrease E.coli and Salmonella in the intestine of broilers, while high concentrations of chitin have adverse effects on these bacteria [44]. In weaning piglets, $8 \% H$. illucens larvae diet had lower counts of Lactobacilli than the control and $4 \%$ H. illucens larvae diet [7]. Thus, dietary inclusion of $8 \%$ H. illucens larvae had no positive effects on the microbiota may be due to the higher level of chitin in the diets. Additionally, recent studies have indicated that insects contain non-protein nitrogen, such as chitin, nucleic acids, ammonia, nitrites, etc., could lead to an overestimation of the insect protein content $[45,46]$. In the present study, we used the conventional nitrogento-protein conversion factor value of 6.25 to express the protein content of $H$. illucens larvae, which may result the true protein content in the diet and colonic digesta were lower in the $\mathrm{H} 2$ group than in the control group. A previous study has showed that non-protein nitrogen can inhibit the growth of beneficial bacteria, such as Lactobacillus, Bifidobacterium, and Megasphaera [47] Therefore, additionally potential explanation for had no beneficial effects on the colonic microbiota may be an increasing of non-protein nitrogen content when pigs fed the dietary inclusion of $8 \% \mathrm{H}$. illucens larvae, but further study will be required to elucidate the underlying mechanisms. Nevertheless, our findings suggest that dietary inclusion of $4 \% \mathrm{H}$. illucens larvae altered the microbiota structure of finishing pigs toward a host-friendly gut environment.

\section{H. illucens larvae significantly increase SCFA concentrations in the colon of finishing pigs}

A change in intestinal microbiota is often accompanied by changes in microbial metabolism [48]. Undigested carbohydrates in stomach and small intestine can be fermented by microbes with the production of SCFAs in the large intestine [14]. SCFAs, including acetate, propionate, and butyrate, play an important role in the metabolic functions of the gut. In the present study, the $H$. illucens larvae induced an increase in the concentration of total SCFAs and butyrate. Previous studies also observed that $H$. illucens larvae as a soybean meal substitute increase the concentration of SCFAs in the cecum of laying hens $[5,11]$. This increase may have been the result of an increased abundance or the number of microbes capable of producing butyrate in the colon. The correlation analysis indicated the trophic linkage between the abundance of Roseburia, Pseudobutyrivibrio, Faecalibacterium, the number of Clostridium cluster XIVa and butyrate concentration in the colonic digesta, suggesting that the increase in Roseburia, Pseudobutyrivibrio, Faecalibacterium, and Clostridium cluster XIVa may have resulted in the increase in colonic butyrate concentration. Additionally, $\mathrm{H}$. illucens larvae are rich in chitin, which can not be degraded or absorbed by the small intestine but can flow into the large intestine, and subsequently be fermented by bacteria in large intestine. Thus, another potential explanation for the increase in butyrate concentration may be attributed to the alteration of substrate for microbial fermentation after administering $H$. illucens larvae. Butyrate is the major energy source for colonic epithelial cells and exerts an anti-inflammatory function [49]. Therefore, the increase in butyrate concentration in the current study suggests a host-friendly gut environment after administering $H$. illucens larvae. 


\section{H. illucens larvae markedly decrease the end products of amino acid fermentation}

Undigested protein or other nitrogenous compounds, such as amino acids, are fermented by microbes to produce BCFAs, biogenic amines, ammonia, phenol and indole compounds [14]. In the present study, $H$. illucens larvae markedly impacted the nitrogen metabolic profiles. For biogenic amines, cadaverine and putrescine are the most abundant amines and are formed from decarboxylation of lysine, arginine and ornithine, respectively [14]. A diet including 4\% $H$. illucens larvae markedly decreased the concentrations of total amines and cadaverine compared with the control group, suggesting decreased microbial amino acid decarboxylation, which may be attributed to a decrease in the abundance of amines-producing bacteria in the colon. Our correlation analysis showed that the decreases in total amines and cadaverine were positively correalted with the decreased abundance of Streptococcus. This finding is consistent with some previous studies, showing that Streptococcus bacteria have amine-producing ability [48, 50]. High levels of biogenic amines, such as cadaverine, might be toxic to gut health [51]. Thus, the decrease in total amines and cadaverine concentrations by $H$. illucens larvae may extert a beneficial effect on gut health.

On the other hand, administering $H$. illucens larvae also altered the aromatic amino acid metabolism by bacteria in the colon. Tryptophan, an aromatic amino acid, can be decarboxylated into tryptamine by gut bacteria [13, 14]. In the present study, diet including $4 \% H$. illucens larvae decreased the tryptamine concentration in the colonic digesta. Tryptamine induces serotonin secretion by enterochromaffin cells and subsequently regulates intestinal motility and platelet function [52]. Therefore, the decrease in tryptamine may affect intestinal function. In addition, $H$. illucens larvae also reduced the concentrations of phenol, $p$-cresol, and skatole, indicating that bacterial fermentation of tryptophan and tyrosine decreased. Phenol and $p$-cresol are produced from tyrosine catabolism by gut bacteria, while skatole is derived from tryptophan catabolism [14], and are regarded as co-carcinogens and colon cancer promoter [53]. Thus, the decrease in the concentrations of phenolic and indolic compounds in the current study indicates that $H$. illucens larvae may have a beneficial effect on gut health. In general, together with the increase in SCFAs, our findings clearly indicate an evident change in microbial metabolic activity, with higher microbial carbohydrate fermentation and lower microbial catabolism of amino acids after the $H$. illucens larvae treatment.

\section{H. illucens larvae affected the colonic mucosal response involved in colonic health}

The change of intestinal microbiota and their metabolites could affect intestinal immunity of host. In the current study, diet including $H$. illucens larvae (especially supplementation with $4 \%$ group) down-regulated mRNA expression of TLR4 and pro-inflammatory cytokines IFN- $\gamma$, while up-regulated the expression of anti-inflammatory cytokines $I L-10$ in the colonic mucosa. As the novel receptors, TLR can mediate innate immune responses, recognize microbiota and their products and then initiate pro-inflammatory pathways [54]. Some species of Streptococcus [55] and their products (amines, indolic and phenolic compounds) [13, 14] can trigger intestinal inflammation through TLR4 signaling pathways, while SCFAs-producing bacteria and SCFAs can down-regulate the pro-inflammatory responses through TLR4-NFkB signaling pathway [56]. In particular, the correlation analysis also revealed that the down-regulation in the expressions of TLR4 and pro-inflammatory cytokines (IFN- $\gamma$ ) positively correlated with the decreased abundance of Streptococcus and the concentrations of total amines, cadaverine, and phenol, while negatively correlated with the increase in butyrate-producing bacteria (Psedobutyrivibrio, Roseburia, Faecalibacterium, Clostridium cluster XIVa) and the concentrations total SCFA, and butyrate (Fig. 7). Thus, the down-regulation gene expression levels of pro-inflammatory cytokines while up-regulation of the anti-inflammatory cytokine after the $H$. illucens larvae treatment may be attributed to enrichments of some butyrate-producing bacteria and SCFAs concentrations, and the depression of potential pathogen (Streptococcus) abundance and several toxic compounds concentrations.

As the critical line, the intestinal barrier can protect against pathogenic agents and luminal antigens. In the current study, dietary inclusion of $H$. illucens larvae up-regulated the expression of intestinal barrier genes expression in the colonic mucosa, such as ZO-1, occludin, and mucin-1, suggesting that $H$. illucens larvae may enhance the integrity of the mucous layer, and then generate a host-friendly gut environment which can defend against pathogen infection. To the best of our knowledge, our study is the first to test partially $H$. illucens larvae inclusion in the diets of finishing pigs, and the available information on the effect of dietary $H$. illucens larvae inclusion on mucosal response involved in colonic health is very limited. A previous study has shown that SCFAs, especially butyrate can maintain the gut integrity [56]. As mentioned above, diet inclusion of $H$. illucens larvae increased the concentrations of total SCFAs and butyrate, and correlation analysis also revealed that the total SCFAs and butyrate concentrations and SCFA-producing bacteria were positively correlated with 
mRNA expression levels of ZO-1, occludin, and mucin-1. Therefore, the high total SCFAs and butyrate concentrations and the abundance or counts of SCFA-producing bacteria after the $H$. illucens larvae treatment may lead to up-regulation of intestinal barrier genes expression, but further studies will be required to clarify the underlying mechanisms. Nonetheless, these findings suggest that diet inclusion of $H$. illucens larvae down-regulated the expression of pro- inflammatory genes, while up-regulated the expression of anti-inflammatory and intestinal barrier genes.

\section{Conclusion}

In conclusion, the present study demonstrates that dietary supplementation with $4 \% \mathrm{H}$. illucens larvae meal significantly altered colonic microbial composition, metabolic profiles, and immune status of finishing pigs, likely toward a host-friendly gut environment. Colonic bacteria, such as Lactobacillus and several butyrate-producing bacteria were increased after $H$. illucens larvae supplementation, whereas the abundance of Streptococcus was decreased. Intestinal metabolism was altered by $\mathrm{H}$. illucens larvae, as evidenced by the increase in the concentrations of SCFAs, and the decrease in the concentrations of metabolites involved in amino-acid metabolism. The colonic mucosal mRNA expression of TLR-4 and pro-inflammatory cytokines were decreased, while the expression of anti-inflammatory and intestinal barrier genes were increased. Furthermore, the changes in the microbiota composition and metabolites concentrations were associated with the alterations in the colonic mucosal immune homeostasis and barrier function. These findings provide a new perspective on insect meal as a sustainable protein source rich in nutrients for swine feed.

\section{Additional files}

Additional file 1: Table S1. Primers used for quantification in this study. (DOCX $16 \mathrm{~kb}$ )

Additional file 2: Table S2. Primers used for host genes in this study. (DOCX $15 \mathrm{~kb}$ )

Additional file 3: Figure S1. Rarefaction curves comparing the number of sequences with the number of phylotypes found in the 16S rRNA gene libraries from the microbiota in the digesta of the colon of pigs. (TIF $12962 \mathrm{~kb}$ )

Additional file 4: Figure S2. Influence of Hermetia illucens larvae meal on the 30 most abundant genera in the colonic digesta. The color represents the relative abundance of bacteria. (TIF $15073 \mathrm{~kb}$ )

Additional file 5: Figure S3. Spearman's correlation analysis between the abundance of colonic microbiota (at the genus level and GPCR) and microbial metabolites affected by dietary treatment. Cells are colored based on the correlation coefficient between the significantly changed bacteria (the relative abundance and the numbers of bacteria) and metabolites (concentrations). The intensity of the colors represents the degree of association. Red represented a significant positive correlation $(P<0.05)$, blue represents significantly negative correlation $(P<0.05)$, and white shows that the correlation was not significant $(P>0.05)$. Total SCFA: total short-chain fatty acids. (TIF $9517 \mathrm{~kb}$ )

\section{Abbreviations}

AMOVA: Analysis of molecular variance; BCFA: Branched-chain fatty acid; FDR: False discovery rate; IFN- $\gamma$ : Interferon- $\gamma$; IL: Interleukin; OTU: Operational taxonomic units; PCoA: Principal coordinate analysis; SCFAs: Short-chain fatty acids; TLR: Toll-like receptors; TNF-a: Tumor necrosis factor-a; ZO-1: Zona occludens protein 1

\section{Acknowledgements}

The authors would like to thank Dr. Dun Deng, Dr. Zhichang Liu, Ms. Zhimei Tian, and Ms. Yiyan Cui for their help in the successful completion of this study.

\section{Funding}

This study was supported by the Presidential Foundation of the Guangdong Academy of Agricultural Sciences (201802B, 201621) and Guangdong Modern Agro-industry Technology Research System (2016LM1080,

2017LM1080). We also would like to thank EditorBar (http://online.editorbar. com) for English language editing.

\section{Availability of data and materials}

The datasets supporting the conclusions of this article are included within the article.

\section{Authors' contributions}

MY, WDC, and XYM conceived and designed the whole trial; ZML and TR conducted the pig trial; MY and ZML conducted laboratory analyses. MY, XYM, and GW wrote the manuscript. All authors read and approved the final manuscript.

\section{Ethics approval and consent to participate}

The experimental proposals and procedures for the care and treatment of the pigs were approved by the Animal Care and Use Committee of Guangdong Academy of Agricultural Sciences (authorization number GAASIAS-2016-017).

\section{Consent for publication}

Not applicable

\section{Competing interests}

The authors declare that they have no competing interests.

\section{Author details}

${ }^{1}$ Institute of Animal Science, Guangdong Academy of Agricultural Sciences, Guangzhou 510640, Guangdong, People's Republic of China. ${ }^{2}$ State Key Laboratory of Livestock and Poultry Breeding, Guangzhou 510640, Guangdong, People's Republic of China. ${ }^{3}$ Key Laboratory of Animal Nutrition and Feed Science in South China, Ministry of Agriculture; Guangdong Public Laboratory of Animal Breeding and Nutrition, Guangzhou 510640,

Guangdong, People's Republic of China. ${ }^{4}$ Guangdong Engineering Technology Research Center of animal Meat quality and Safety Control and Evaluation, Guangzhou 510640, Guangdong, People's Republic of China.

Received: 25 January 2019 Accepted: 25 April 2019

Published online: 19 June 2019

References

1. Food and Agriculture Organization of the United Nations (FAO). Edible insects - prospects for food and feed security. In: FAO Forestry Paper No. 171. Rome, Italy: FAO; 2013. p. ix.

2. Makkar HPS, Tran G, Heuzé V, Ankers P. State-of-the-art on use of insects as animal feed. Anim Feed Sci Tech. 2014;197:1-33.

3. Van Huis A. Potential of insects as food and feed in assuring food security. Annu Rev Entomol. 2013;58(1):563-83.

4. Barragan-Fonseca KB, Dicke M, van Loon JJ. Nutritional value of the black soldier fly (Hermetia illucens $\mathrm{L}$ ) and its suitability as animal feed-a review. J Insects Food Feed. 2017;3(2):105-20.

5. Cutrignelli MI, Messina M, Tulli F, Randazzo B, Olivotto I, Gasco L, et al. Evaluation of an insect meal of the black soldier Fly (Hermetia illucens) as soybean substitute: intestinal morphometry, enzymatic and microbial activity in laying hens. Res Vet Sci. 2018;117:209-15. 
6. Maurer V, Holinger M, Amsler Z, Früh B, Wohlfahrt J, Stamer A, et al. Replacement of soybean cake by Hermetia illucens meal in diets for layers. J Insects Food Feed. 2016;2(2):83-90.

7. Spranghers T, Michiels J, Vrancx J, Ovyn A, Eeckhout M, Clercq PD, et al. Gut antimicrobial effects and nutritional value of black soldier fly (Hermetia illucens L) prepupae for weaned piglets. Anim Feed Sci Tech. 2018;235: S0377840117307721.

8. Waśko A, Bulak P, Polak-Berecka M, Nowak K, Polakowski C, Bieganowski A. The first report of the physicochemical structure of chitin isolated from Hermetia illucens. Int J Biol Macromol. 2016;92:316-20.

9. Xu YQ, Wang ZQ, Wang YL, Yan SM, Shi BL. Effects of chitosan as growth promoter on diarrhea, nutrient apparent digestibility, fecal microbiota and immune response in weaned piglets. J Applied Anim Res. 2018;46(1):1437-42.

10. Cullere M, Tasoniero G, Giaccone V, Miotti-Scapin R, Claeys E, De Smet S, et al. Black soldier fly as dietary protein source for broiler quails: apparent digestibility, excreta microbial load, feed choice, performance, carcass and meat traits. Animal. 2016;10(12):1923-30.

11. Borrelli L, Coretti L, Dipineto L, Bovera F, Menna F, Chiariotti L, et al. Insectbased diet, a promising nutritional source, modulates gut microbiota composition and SCFAs production in laying hens. Sci Rep. 2017;7(1):16269. https://doi.org/10.1038/s41598-017-16560-6.

12. Peng L, Li ZR, Green RS, Holzman IR, Lin J. Butyrate enhances the intestinal aarrier by facilitating tight junction assembly via activation of AMP-activated protein kinase in Caco-2 cell monolayers. J Nutr. 2009;139(9):1619-25. https://doi.org/10.3945/jn.109.104638.

13. Rist VTS, Weiss E, Eklund M, Mosenthin R. Impact of dietary protein on microbiota composition and activity in the gastrointestinal tract of piglets in relation to gut health: a review. Animal. 2013;7(7):1067-78.

14. Davila AM, Blachier F, Gotteland M, Andriamihaja M, Benetti PH, Sanz Y, et al. Re-print of "intestinal luminal nitrogen metabolism: role of the gut microbiota and consequences for the host". Pharmacol Res. 2013;68(1):95-107.

15. Lee J, Kim YM, Park YK, Yang YC, Jung BG, Lee BJ. Black soldier fly (Hermetia illucens) larvae enhances immune activities and increases survivability of broiler chicks against experimental infection of Salmonella Gallinarum. J Vet Med Sci. 2018;80:736-40.

16. AOAC. Official methods of analysis. 18th ed. Gaithersburg, MD: Association of Official Analytical Chemists. 2007.

17. NRC. Nutrient requirements of swine. 11th ed Washington, DC: Natl Acad Press. 2012.

18. Yu M, Mu CL, Yang YX, Zhang CJ, Su Y, Huang Z, et al. Increases in circulating amino acids with in- feed antibiotics correlated with gene expression of intestinal amino acid transporters in piglets. Amino Acids. 2017;49(9):1587-99. https://doi.org/10.1007/s00726-017-2451-0.

19. AOAC. Official methods of analysis, 18th ed. AOAC Int, Arlington, VA. 2004

20. Bovera F, Loponte R, Marono S, Piccolo G, Parisi G, laconisi V, et al. Use of larvae meal as protein source in broiler diet: effect on growth performance, nutrient digestibility, and carcass and meat traits. J Anim Sci. 2016;94(2):639-47.

21. Yu M, Zhang CJ, Yang YX, Mu CL, Su Y, Yu KF, et al. Long-term effects of early antibiotic intervention on blood parameters, apparent nutrient digestibility, and fecal microbial fermentation profile in pigs with different dietary protein levels. $J$ Anim Sci Biotechnol. 2017;8(1):60. https://doi.org/10.1186/s40104-017-0192-2

22. Chaney AL, Marbach EP. Modified reagents for determination of urea and ammonia. Clin Chem. 1962;8(8):130-2

23. Yang $Y X, M u ~ C L$, Zhang JF, Zhu WY. Determination of biogenic amines in digesta by high performance liquid chromatography with precolumn dansylation. Anal Lett. 2014;47(8):1290-8.

24. Schüssler W, Nitschke L. Death of fish due to surface water pollution by liquid manure or untreated wastewater: analytical preservation of evidence by HPLC. Water Res. 1999;33(12):2884-7.

25. Mao SY, Zhang ML, Liu JH, Zhu WY. Characterising the bacterial microbiota across the gastrointestinal tracts of dairy cattle: membership and potential function. Sci Rep. 2015;5:16116. https://doi.org/10.1038/srep16116.

26. Caporaso JG, Lauber CL, Walters WA, Berg-Lyons D, Huntley J, Fierer N, et al. Ultra-high-throughput microbial community analysis on the Illumina HiSeq and MiSeq platforms. ISME J. 2012;6:1621. https://doi.org/10.1038/ismej.2012.8.

27. Campbell BJ, Polson SW, Hanson TE, Mack MC, Schuur EAG. The effect of nutrient deposition on bacterial communities in Arctic tundra soil. Environ Microbiol. 2010;12(7):1842-54

28. Gao K, Pi Y, Peng Y, Mu CL, Zhu WY. Time-course responses of ileal and fecal microbiota and metabolite profiles to antibiotics in cannulated pigs. Appl Microbiol Biot. 2018;102(5):2289-99.
29. Edgar RC. Search and clustering orders of magnitude faster than BLAST. Bioinformatics. 2010;26(19):2460.

30. Schloss PD, Westcott SL, Thomas R, Hall JR, Martin H, Hollister EB, et al. Introducing mothur: open-source, platform-independent, communitysupported software for describing and comparing microbial communities. Appl Environ Microbiol. 2009.

31. Benjamini $Y$, Hochberg Y. Controlling the false discovery rate: a practical and powerful approach to multiple testing. J R Stat Soc. 1995;57(1):289-300.

32. Scott KP, Gratz SW, Sheridan PO, Flint HJ, Duncan SH. The influence of diet on the gut microbiota. Pharmacol Res. 2013;69(1):52-60.

33. Flint HJ, Scott KP, Louis P, Duncan SH. The role of the gut microbiota in nutrition and health. Nat Rev Gastroenterol Hepatol. 2012;9:577. https://doi. org/10.1038/nrgastro.2012.156.

34. Louis P, Hold GL, Flint HJ. The gut microbiota, bacterial metabolites and colorectal cancer. Nat Rev Microbiol. 2014;12:661. https://doi.org/10.1038/ nrmicro3344.

35. Louis P, Scott KP, Duncan SH, Flint HJ. Understanding the effects of diet on bacterial metabolism in the large intestine. J Appl Microbiol. 2010;102(5): 1197-208.

36. Boleij A, Tjalsma $\mathrm{H}$. The itinerary of Streptococcus gallolyticus infection in patients with colonic malignant disease. Lancet Infect Dis. 2013;13(8):719-24.

37. Janda WM. The genus Streptococcus - part I: emerging pathogens in the "Pyogenic Cocci" and the "Streptococcus bovis" groups. Clin Microbiol Newsl. 2014;36(20):157-66.

38. Wang T, Cai G, Qiu Y, Fei N, Zhang M, Pang $X$, et al. Structural segregation of gut microbiota between colorectal cancer patients and healthy volunteers. ISME J. 2012;6(2):320-9.

39. Terada A, Hara H, Sato D, Higashi T, Nakayama S, Tsuji K, et al. Effect of dietary chitosan on faecal microbiota and faecal metabolites of humans. Microb Ecol Health Dis. 2011:8(1):15-21.

40. Neyrinck AM, Possemiers S, Verstraete W, Backer FD, Cani PD, Delzenne NM. Dietary modulation of clostridial cluster XIVa gut bacteria ( Roseburia spp.) by chitin-glucan fiber improves host metabolic alterations induced by highfat diet in mice. J Nutr Biochem. 2012;23(1):51-9.

41. Decuypere JA, Dierick NA. The combined use of triacylglycerols containing medium-chain fatty acids and exogenous lipolytic enzymes as an alternative to in-feed antibiotics in piglets: concept, possibilities and limitations. An overview. Nutr Res Rev. 2003;16(2):193-210.

42. Skřivanová E, Marounek M, Dlouhá G, Kaňka J. Susceptibility of Clostridium perfringens to C-C fatty acids. Lett Appl Microbiol. 2005:41(1):77-81.

43. Yi HY, Chowdhury M, Huang YD, Yu XQ. Insect antimicrobial peptides and their applications. Appl Microbiol Biotech. 2014;98(13):5807-22.

44. Khempaka S, Chitsatchapong C, Molee W. Effect of chitin and protein constituents in shrimp head meal on growth performance, nutrient digestibility, intestinal microbial populations, volatile fatty acids, and ammonia production in broilers. J Appl Poul Res. 2011;20(1):1-11. https:// doi.org/10.3382/japr.2010-00162.

45. Janssen RH, Vincken JP, van den Brock LAM, Fogliano V, Lakemond CMM. Nitrogen-to-protein conversion factors for three edible insects: Tenebrio molitor, Alphitobius diaperinus, and Hermetia illucens. J Agri Food Chem. 2017;65(11):2275-8.

46. Nery J, Gasco L, Dabbou S, Schiavone A. Protein composition and digestibility of black soldier fly larvae in broiler chickens revisited according to the recent nitrogen-protein conversion ratio. J Insects Food Feed. 2018;4(3):171-7.

47. Benno Y, Endo K, Suzuki K, Mitsuoka T, Namioka S. Use of nonprotein nitrogen in pigs: effects of dietary urea on the intestinal microflora. Am J Vet Res. 1985;46(4):959-62.

48. Mu CL, Yang YX, Luo Z, Guan LL, Zhu WY. The colonic microbiome and epithelial transcriptome are altered in rats fed a high-protein diet compared with a normal-protein diet. J Nutr. 2016;146(3):474-83.

49. Tremaroli V, Bäckhed F. Functional interactions between the gut microbiota and host metabolism. Nature. 2012:71(7415):242-9.

50. Yu M, Mu CL, Zhang CJ, Yang YX, Su Y, Zhu WY. Marked response in microbial community and metabolism in the ileum and cecum of suckling piglets after early antibiotics xxposure. Front Microbiol. 2018;9:1166.

51. Holmes E, Li JV, Athanasiou T, Ashrafian H, Nicholson JK. Understanding the role of gut microbiome-host metabolic signal disruption in health and disease. Trends Microbiol. 2011:19(7):349-59.

52. Yano JM, Kristie Y, Donaldson GP, Shastri GG, Phoebe A, Liang M, et al. Indigenous bacteria from the gut microbiota regulate host serotonin biosynthesis. Cell. 2015;161(2):264-76. 
53. Nowak A, Libudzisz Z. Influence of phenol, p-cresol and indole on growth and survival of intestinal lactic acid bacteria. Anaerobe. 2006;12(2):80-4.

54. Abreu MT. Toll-like receptor signalling in the intestinal epithelium: how bacterial recognition shapes intestinal function. Nat Rev Immunol. 2010; 10(2):131-44.

55. Li B, Xi P, Wang Z, Han X, Xu Y, Zhang Y, et al. PI3K/Akt/mTOR signaling pathway participates in Streptococcus uberis-induced inflammation in mammary epithelial cells in concert with the classical TLRs/NF-KB pathway. Vet Microbiol. 2018;227:103-11.

56. Wang J, Tian SY, Yu H, Wang J, Zhu WY. The response of colonic mucosaassociated microbiota composition, mucosal immune homeostasis, and barrier function to early-life galactooligosaccharides intervention in suckling piglets. J Agric Food Chem. 2018;67(2):578-88.

Ready to submit your research? Choose BMC and benefit from:

- fast, convenient online submission

- thorough peer review by experienced researchers in your field

- rapid publication on acceptance

- support for research data, including large and complex data types

- gold Open Access which fosters wider collaboration and increased citations

- maximum visibility for your research: over $100 \mathrm{M}$ website views per year

At $\mathrm{BMC}$, research is always in progress.

Learn more biomedcentral.com/submissions 